\title{
EMBRIOGÊNESE SOMÁTICA DO CAQUIZEIRO ${ }^{1}$
}

\author{
DAYSE CRISTINA DE CARVALHO ${ }^{2}$, LUIZ ANTONIO BIASI ${ }^{3}$, LUCIANA LOPES FORTES RIBAS ${ }^{4}$, \\ CHARLES ALLAN TELLES ${ }^{5}$, FLÁVIO ZANETTE ${ }^{6}$
}

\begin{abstract}
RESUMO - O objetivo deste trabalho foi o estabelecimento de um protocolo para a embriogênese somática do caquizeiro. Como explantes, foram utilizados embriões zigóticos em diversos estádios de desenvolvimento, retirados de frutos coletados de plantas adultas a campo, a partir de quatro semanas após o pleno florescimento até 22 semanas. O meio básico para os experimentos foi o $\mathrm{MS} 1 / 2 \mathrm{NO}_{3}$. O meio inicial de indução foi suplementado com $20 \mu \mathrm{M}$ de 2,4-D e $2 \mu \mathrm{M}$ de cinetina. Os calos escuros obtidos foram repicados para outro meio de indução, com concentrações 10 ou $20 \mu \mathrm{M}$ de $2,4-$ $\mathrm{D}$ e $2 \mu \mathrm{M}$ de cinetina. Os calos com massas pró-embriogênicas obtidos foram transferidos para meio de manutenção e multiplicação com $2 \mu \mathrm{M}$ de cinetina e 2,4-D nas concentrações 2,5; 5,0 e $10 \mu \mathrm{M}$. As massas embriogênicas formadas foram transferidas para meio de maturação suplementado com $0,5 \mu \mathrm{M}$ de AIB e as concentrações 5; 10 e $20 \mu \mathrm{M}$ de 2-iP. Os embriões formados foram isolados em dois meios de conversão, sendo o primeiro com 5 $\mu \mathrm{M}$ de 2-iP, $5 \mu \mathrm{M}$ de $\mathrm{AG}_{3}$ e $0,5 \mu \mathrm{M}$ de AIB e o segundo com $0,5 \mu \mathrm{M}$ de $\mathrm{AG}_{3}$ e BAP, nas concentrações $0 ; 0,25$; 0,5 e 1,0 $\mu \mathrm{M}$. Como resultados, obtevese o padrão indireto de embriogênese somática a partir de embriões zigóticos maduros, com mais de 22 semanas de formação, quando cultivados em meio de cultura com $10 \mu \mathrm{M}$ de 2,4-D combinado com $2 \mu \mathrm{M}$ de cinetina. A manutenção e a multiplicação das culturas embriogênicas foram mais eficientes com $5 \mu \mathrm{M}$ de 2,4-D, na qual os pró-embriões avançaram para o estádio globular. Na fase de maturação, as concentrações de 2-iP testadas atuaram promovendo os embriões globulares a estádios mais avançados da ontogenia como cordiforme, torpedo e cotiledonar. A suplementação do meio de cultura com $1 \mu \mathrm{M}$ de BAP e $0,5 \mu \mathrm{M}$ de $\mathrm{AG}_{3}$ gerou a formação de plantas mais desenvolvidas, com maior número e tamanho de folhas.
\end{abstract}

Termos para Indexação: Diospyros kaki, cultura de tecidos, fruticultura, micropropagação.

\section{SOMATIC EMBRYOGENESIS OF JAPANESE PERSIMMON}

ABSTRACT - The goal of this work was to develop a protocol for persimmon cloning through somatic embryogenesis. Zygotic embryos excised from fruits collected from adult plants were tested at several developmental phases. They were collected during 22 weeks after 4 weeks blossoming. The basic medium tested was $\mathrm{MS} 1 / 2 \mathrm{NO}_{3}$. Initial induction medium was supplemented with $20 \mu \mathrm{M} 2,4-\mathrm{D}+2 \mu \mathrm{M}$ kinetin. Dark calluses obtained were transferred to induction medium, with concentrations of 10 and $20 \mu \mathrm{M} 2,4-\mathrm{D}+2 \mu \mathrm{M}$ kinetin. The calli with pro-embryogenic masses were transferred to a maintenance and multiplication medium, with $2 \mu \mathrm{M}$ kinetin and 2,4-D at the concentrations of 2.5, 5.0 and $10 \mu \mathrm{M}$. Embryogenic masses formed were transferred to a maturation medium supplemented with $0.5 \mu \mathrm{M} \mathrm{IBA}$ and 5, 10 and 20 $\mu \mathrm{M} 2 \mathrm{iP}$. Embryos formed were isolated in two conversion media, one with $5 \mu \mathrm{M} 2-\mathrm{iP}+5 \mu \mathrm{M} \mathrm{GA}_{3}$ and $0.5 \mu \mathrm{M} \mathrm{IBA}$, and another medium with $0.5 \mu \mathrm{M} \mathrm{GA}_{3}$ and BAP at $0,0.25,0.5$ and $1.0 \mu \mathrm{M}$. Indirect somatic embryogenesis were obtained from mature zygotic embryos collected after 22 weeks, when cultivated in culture medium with $10 \mu \mathrm{M} 2,4 \mathrm{D}$ combined with $2 \mu \mathrm{M}$ kinetin. Embryos maintenance and multiplication were more efficient with $5 \mu \mathrm{M} 2,4-\mathrm{D}$, in which the pro-embryos advanced to the globular embryos phase. At the maturation phase the concentrations of 2-iP tested promoted globular embryos to more advanced stages of ontogeny, such as cordiform, torpedo and cotiledonary. Supplementation of the culture medium with $1 \mu \mathrm{M}$ BAP generated better developed plants, with highest number of leaves and size.

Index Terms: Diospyros kaki, tissue culture, fruit production, micropropagation.

\section{INTRODUÇÃO}

A propagação convencional de caquizeiros pela via sexuada é difícil, devido ao seu longo período juvenil, elevado porte das plantas e heterozigoze. Além disso, o cruzamento é prejudicado pelo limitado número de cultivares, que carregam flores masculinas e/ou hermafroditas (Choi et al., 2001). A propagação vegetativa via enxertia é também dificultada pelo fato de os porta-enxertos serem provenientes de sementes, o que causa grande desuniformidade quanto ao porte e vigor das plantas, além de ser um processo demorado, oneroso e com baixas taxas de pegamento (Biasi et al., 2002).

A solução para este problema passa pelo desenvolvimento de uma tecnologia de propagação vegetativa para a formação direta das mudas ou de porta-enxertos, o que representará um significativo avanço na cultura do caquizeiro (Martins \& Pereira, 1989).

Barros (1999) ressalta que dentre os processos de micropropagação, a embriogênese somática é, teoricamente, a melhor opção para a propagação in vitro de fruteiras por apresentar algumas vantagens, tais como: a alta taxa de multiplicação comparada a qualquer outro processo de propagação; o escalonamento da produção pela manutenção da cultura em meio líquido; o plantio direto da muda obtida via embriogênese somática sem necessidade de enxertia, com menor custo de produção, além de a planta ser geneticamente igual à plantamãe, sem as influências do porta-enxerto, como acontece com as plantas obtidas por métodos de propagação vegetativa convencionais.

O trabalho pioneiro com a indução da embriogênese somática a partir de tecidos de caquizeiro foi realizado por Hirokazu et al. (1998), no Japão, trabalhando com segmentos foliares provenientes de plantas obtidas de ápices meristemáticos cultivados in vitro, em meio $\mathrm{MS}^{1} / 2 \mathrm{NO}_{3}$ suplementado com BAP e ANA, em diferentes concentrações. Posteriormente, não se encontraram trabalhos semelhantes publicados, ainda que se saiba que a técnica de indução da embriogênese somática seja uma ferramenta com grande potencial para a propagação massal do caquizeiro. Assim, o objetivo deste trabalho foi o estabelecimento de um protocolo para a embriogênese somática do caquizeiro a partir de embriões zigóticos. Esse protocolo poderá servir de embasamento para futuros estudos com tecidos somáticos, já que os tecidos de origem zigótica apresentam variabilidade natural decorrente do cruzamento.

\section{MATERIAL EMÉTODOS}

Os experimentos foram conduzidos no Laboratório de

\footnotetext{
${ }^{1}$ (Trabalho 140/2003). Recebido: 03/06/2003. Aceito para publicação: 24/05/2004.

${ }^{2}$ Eng $^{\mathrm{a}}$ Agra , MSc. Aluna do Programa de Pós-Graduação em Agronomia. ESALQ/USP. E-mail: dayse @ esalq.usp.br.

${ }^{3}$ Professor Adjunto do Departamento de Fitotecnia e Fitossanitarismo. Setor de Ciências Agrárias. UFPR. Caixa Postal 19.061. CEP 81.531-990. Curitiba-PR. Fone/ Fax (41) 350-5601. E-mail: biasi@ ufpr.br. Bolsista de Produtividade em Pesquisa do CNPq.

${ }^{4}$ Professora Adjunta do Departamento de Botânica. Setor de Ciências Biológicas. UFPR.

${ }^{5}$ Aluno do Curso de Agronomia. UFPR. Bolsista de Iniciação Científica do CNPq.

${ }^{6}$ Professor Titular do Departamento de Fitotecnia e Fitossanitarismo. Setor de Ciências Agrárias. UFPR.
} 
Micropropagação de Plantas do Departamento de Fitotecnia e Fitossanitarismo do Setor de Ciências Agrárias da Universidade Federal do Paraná. Como explantes, foram utilizados embriões zigóticos em diversos estádios de desenvolvimento, retirados de frutos coletados de plantas adultas de caquizeiro do tipo 'Café', a partir de quatro semanas após o pleno florescimento até 22 semanas. A assepsia foi realizada nos frutos inteiros quando possuíam até $3,5 \mathrm{~cm}$ de diâmetro e posteriormente nas sementes, com etanol $70 \%$ por um minuto, imersão em solução de hipoclorito de sódio $2,5 \%$ por trinta minutos e quatro lavagens em água esterilizada.

Efeito do estádio de desenvolvimento do embrião zigótico na indução de culturas embriogênicas.

Foi avaliado o melhor estádio de desenvolvimento do embrião zigótico para induzir a formação de massas embriogênicas, sendo testados seis estádios, a partir de quatro semanas após o florescimento, até a maturação com 22 semanas. Em cada coleta, foram isolados 40 embriões em dois meios de cultura, um livre de reguladores e outro contendo $20 \mu \mathrm{M}$ de 2,4-D e $2 \mu \mathrm{M}$ de cinetina. O meio de cultura utilizado foi o $\mathrm{MS}^{1} / 2 \mathrm{NO}_{3}$ solidificado com 5,5 g. $\mathrm{L}^{-1}$ de ágar. Os frascos foram mantidos no escuro e avaliados após 90 dias pela porcentagem de explantes com calo. Os 40 calos obtidos no primeiro isolamento foram repicados para dois meios de cultura, um com $10 \mu \mathrm{M}$ e outro com $20 \mu \mathrm{M}$ de 2,4-D, ambos acrescidos com $2 \mu \mathrm{M}$ de cinetina. Os explantes foram mantidos no escuro e avaliados após 60 dias do isolamento, pela porcentagem de calos com massas pró-embriogênicas.

Efeito de reguladores de crescimento na manutenção e multiplicação das culturas embriogênicas

As culturas pró-embriogênicas obtidas no experimento anterior foram identificadas e utilizadas neste experimento. O meio de cultura utilizado foi o $\mathrm{MS}^{1 / 2} / 2 \mathrm{NO}_{3} \operatorname{com} 2 \mu \mathrm{M}$ de cinetina e as concentrações de 2,5; 5 e $10 \mu \mathrm{M}$ de 2,4-D. O delineamento foi em blocos ao acaso, com cinco repetições e dez calos por parcela. Os explantes permaneceram no escuro e foram avaliados após 90 dias pela porcentagem de calos com culturas embriogênicas e número de embriões globulares por calo.

\section{Efeito de reguladores de crescimento na maturação dos embriões} somáticos

As culturas embriogênicas desenvolvidas no experimento anterior foram identificadas e utilizadas neste experimento. $\mathrm{O}$ meio de cultura utilizado foi o $\mathrm{MS} 1 / 2 \mathrm{NO}_{3}$ com $0,5 \mu \mathrm{M}$ de AIB e as concentrações de 5; 10 e $20 \mu \mathrm{M}$ de 2-iP. O delineamento foi em blocos ao acaso, com cinco repetições e dez calos por parcela. Os explantes foram mantidos no escuro e avaliados após 60 dias pela porcentagem de calos com massas embriogênicas, número de embriões globulares, cordiformes, torpedos e cotiledonares por calo.

Efeito de reguladores de crescimento na conversão de embriões somáticos em plantas

Os primeiros cinqüenta embriões formados foram individualizados e cultivados em meio de cultura $\mathrm{MS}^{1} / 2 \mathrm{NO}_{3} \operatorname{com} 5 \mu \mathrm{M}$ de 2-iP, $5 \mu \mathrm{M}$ de $\mathrm{AG}_{3}$ e $0,5 \mu \mathrm{M}$ de AIB para a sua conversão em plantas. As culturas foram mantidas na luz, e a avaliação foi realizada após 30 dias pela porcentagem de embriões convertidos em plantas, comprimento médio da raiz e da parte aérea e número de folhas por planta.

Depois foi instalado um experimento de conversão, testando diferentes concentrações de BAP. O meio de cultura foi o $\mathrm{MS}^{1} / 2 \mathrm{NO}_{3}$ suplementado com $0,5 \mu \mathrm{M}$ de $\mathrm{AG}_{3}$ e $0 ; 0,25 ; 0,5$ e $1,0 \mu \mathrm{M}$ de BAP. O delineamento foi em blocos ao acaso, com 3 repetições e 10 embriões por parcela. Os embriões foram mantidos na luz, e a avaliação foi realizada após 30 dias pela porcentagem de embriões convertidos em plantas, porcentagem de embriões oxidados, comprimento da parte aérea e da raiz, e número de folhas por planta.

A sala de crescimento possuía iluminação com lâmpadas fluorescentes do tipo branca fria, fotoperíodo de 16 horas e intensidade luminosa de $40 \mu \mathrm{mol} \cdot \mathrm{m}^{-2} \cdot \mathrm{s}^{-1}$.

A análise estatística foi realizada com o programa computacional MSTAT, sendo que, inicialmente, os dados foram analisados pelo teste de Bartllet para testar a homogeneidade das variâncias dos tratamentos e aqueles não-homogêneos foram transformados para a análise. Depois foi realizada a análise de variância e o teste de Tukey, a 5\% de probabilidade de erro, quando o efeito dos tratamentos foi significativo pelo teste F.

\section{RESULTADOSE DISCUSSÃO}

Efeito do estádio de desenvolvimento do embrião zigótico na indução de culturas embriogênicas

Quanto às fontes de explantes testadas no presente trabalho, apenas os embriões zigóticos maduros (frutos com 22 semanas de formação) permitiram a indução e o desenvolvimento dos embriões somáticos no meio suplementado com reguladores de crescimento. Os explantes isolados em meio de cultura sem reguladores de crescimento não formaram calos. A formação de calos escuros ocorreu em $86,7 \%$ dos quarenta explantes isolados de frutos a partir de 18 semanas de desenvolvimento, em meio suplementado com $20 \mu \mathrm{M}$ de 2,4-D mais 2 $\mu \mathrm{M}$ de cinetina, indicando que embriões com idade inferior apresentam fatores intrínsecos à sua maturidade fisiológica que bloquearam uma resposta aos reguladores de crescimento nas concentrações testadas e ao desencadeamento do processo de embriogênese somática.

Aos 150 dias de cultivo dos explantes, foi possível verificar a formação de complexos ou massas celulares pró-embriogênicas em 52\% dos calos cultivados em meio suplementado com $10 \mu \mathrm{M}$ de 2,4-D mais 2 $\mu \mathrm{M}$ de cinetina (TABELA 1 ). Estes complexos caracterizam-se por serem regiões friáveis, normalmente branco-translúcidas e mucilaginosas quando comparados com calos não-embriogênicos que foram esverdeados e duros. Os embriões maduros apresentaram o padrão indireto de embriogênese, induzindo inicialmente uma massa celular embriogênica, com embriões somáticos desenvolvendo-se em sua superfície (FIGURA 1).

TABELA 1 - Efeito das concentrações 10 e $20 \mu \mathrm{M}$ de $2,4-\mathrm{D}$ mais $2 \mu \mathrm{M}$ de cinetina na indução de calos com massas próembriogênicas a partir de calos obtidos em meio de cultura com $20 \mu \mathrm{M}$ de 2,4-D e $2 \mu \mathrm{M}$ de cinetina (150 dias de cultivo).

\begin{tabular}{ccc}
\hline 2,4-D ( $M)$ & $\begin{array}{c}\text { n (número de calos } \\
\text { avaliados) }\end{array}$ & $\begin{array}{c}\text { Calos com massas pró- } \\
\text { embriogênicas (\%) }\end{array}$ \\
\hline 10 & 40 & 52,00 \\
20 & 40 & 15,15 \\
\hline
\end{tabular}

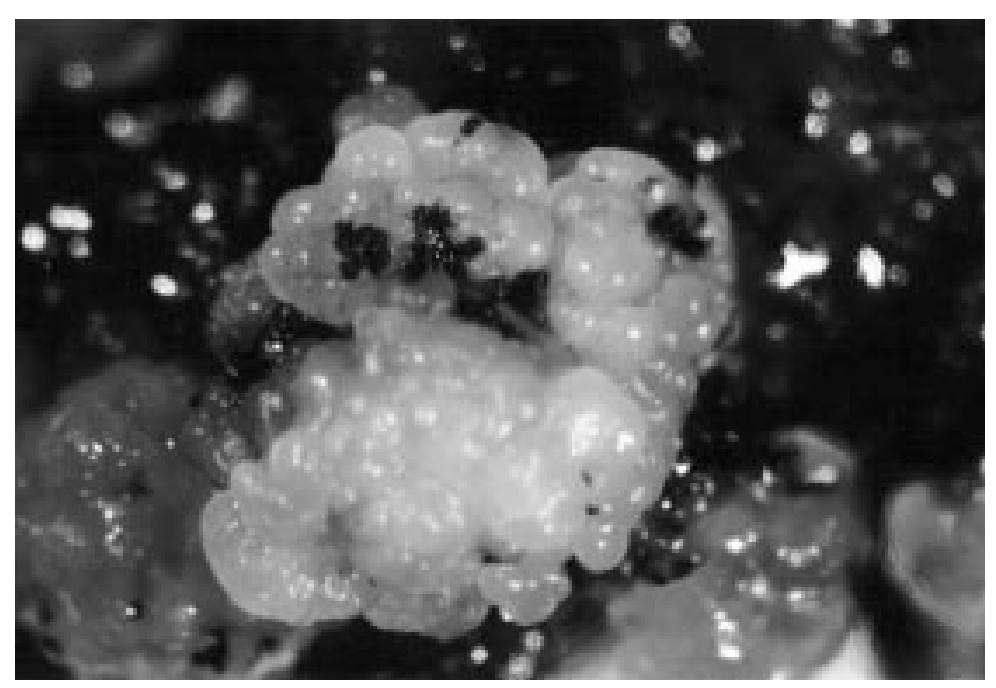

FIGURA 1 - Complexos celulares pró-embriogênicos formados a partir de embriões zigóticos em meio $\mathrm{MS}^{1} / 2 \mathrm{NO}_{3}$ com $10 \mu \mathrm{M}$ de 2,4-D e $2 \mu \mathrm{M}$ de cinetina, aos 150 dias de cultivo. 


\section{Efeito de reguladores de crescimento na manutenção e multiplicação} das culturas embriogênicas

Houve uma evolução dos pró-embriões para o estádio globular, mais pronunciadamente no tratamento com $5 \mu \mathrm{M}$ de 2,4-D, apesar de não diferir significativamente das demais concentrações (TABELA 2). A transferência das culturas embriogênicas para um meio sem reguladores de crescimento ou com a concentração de 2,4-D reduzida é normalmente necessária para a produção de embriões somáticos (Sharp et al., 1980). Nesta etapa, a estratégia consiste em determinar as condições adequadas para o estabelecimento de ciclos repetitivos de divisão celular e o controle restrito dos processos de diferenciação, de tal maneira que as culturas sejam constituídas por células pró-embrionárias ou embriões somáticos em estádios iniciais de desenvolvimento (Guerra et al., 1999). Observouse, na superfície das massas celulares de caquizeiro, a formação de embriões somáticos globulares (FIGURA 2), e a manutenção destas culturas em meio basal, acrescido de 2,4-D, nas três concentrações testadas, induziu a formação de pró-embriões e embriões somáticos globulares num processo contínuo.

TABELA 2 - Efeito das concentrações 2,5; 5,0 e 10ìM de 2,4-D mais 2 $\mu \mathrm{M}$ de cinetina na manutenção e multiplicação das culturas embriogênicas (90 dias de cultivo).

\begin{tabular}{cccc}
\hline $\begin{array}{c}\text { 2,4-D } \\
(\mathbf{M})\end{array}$ & $\begin{array}{c}\text { n (número } \\
\text { de calos } \\
\text { avaliados) }\end{array}$ & $\begin{array}{c}\text { Calos com massas } \\
\text { embriogênicas }(\%)^{\mathbf{1}}\end{array}$ & $\begin{array}{c}\mathbf{N}^{\mathbf{0}} \text { de embriões } \\
\text { globulares/calo }\end{array}$ \\
\hline 2,5 & 50 & 26,00 & 10,96 \\
5,0 & 50 & 17,33 & 38,88 \\
10,0 & 50 & 11,33 & 1,60 \\
\hline $\mathrm{CV} \%$ & - & 18,70 & 9,99 \\
\hline
\end{tabular}

As médias não diferiram significativamente pelo teste $\mathrm{F}$ da análise de variância. ${ }^{1}$ Dados transformados por $\log (\mathrm{x}+10)$

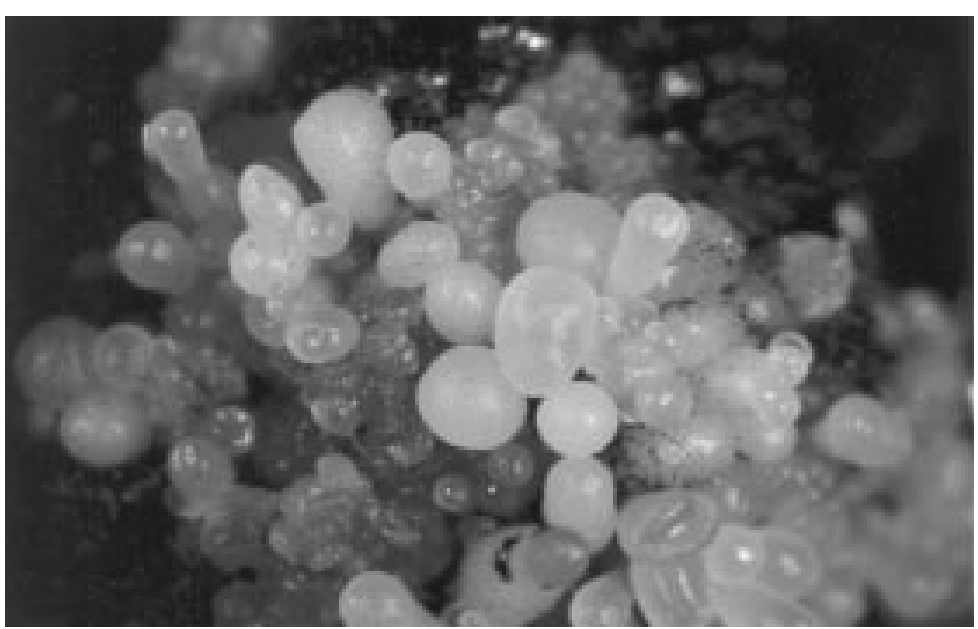

FIGURA 2 - Embriões somáticos globulares formados em meio $\mathrm{MS}^{1} / 2 \mathrm{NO}_{3}$ com $5 \mu \mathrm{M}$ de 2,4-D e $2 \mu \mathrm{M}$ de cinetina, aos 90 dias de cultivo.

Efeito de reguladores de crescimento na maturação dos embriões somáticos

As culturas constituídas de embriões somáticos globulares, que foram transferidas para meios de cultura suplementados com citocininas, apresentaram avanço para outros estádios ontogenéticos, como cordiforme, torpedo e cotiledonar, desenvolvendo-se de forma assincrônica, não havendo diferença estatística entre as concentrações de 2-iP (TABELA 3). Nesta fase da embriogênese somática, compreende a progressão das fases iniciais para as fases tardias. A estratégia a ser empregada consiste em interromper os ciclos repetitivos de divisão celular e fornecer estímulos fisiológicos, bioquímicos e ambientais para a diferenciação celular, para que os ciclos de desenvolvimento e de maturação originem um grande número de embriões somáticos maduros, de alta qualidade e aptos a se converterem em plantas (Guerra et al., 1999). Segundo Gray (1992), os embriões somáticos que se formam a partir de complexos pró-embrionários tendem a se desenvolver de forma assincrônica, sendo que, em determinado tempo, vários estádios ontogenéticos são observados nas culturas (FIGURA 3). Da mesma forma, Guerra \& Handro (1998), trabalhando com culturas embriogênicas de Euterpe edulis repicados para meio de cultura contendo 2-iP e ANA, obtiveram a progressão dos embriões somáticos ao mesmo tempo que a cultura-matriz mantinha a sua competência embriogênica.

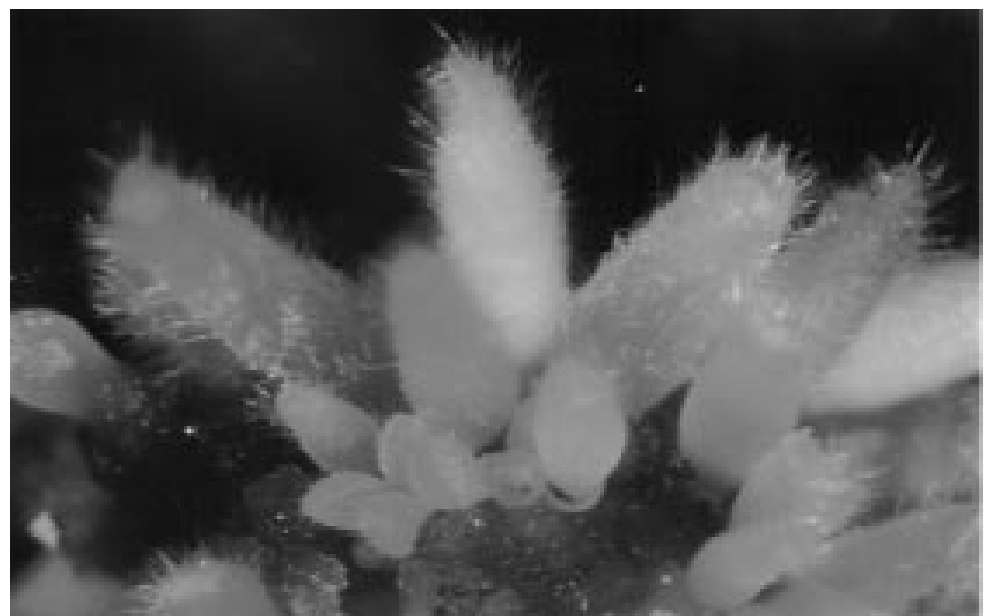

FIGURA 3 - Embriões somáticos em estádio torpedo e cotiledonar, aos 60 dias de cultivo em meio $\mathrm{MS}^{1} / 2 \mathrm{NO}_{3}$ com 10ìM de 2-iP.

Efeito de reguladores de crescimento na conversão de embriões somáticos em plantas

No teste preliminar de conversão, obteve-se, a partir de cinqüienta embriões no estádio torpedo, a conversão em plantas de 75,5\% destes, com uma média de $0,85 \mathrm{~cm}$ de comprimento de raiz, $1,25 \mathrm{~cm}$ de parte aérea e 1,31 folha por plântula quando cultivados em meio suplementado com $5 \mu \mathrm{M}$ de 2-iP, $5 \mu \mathrm{M}$ de $\mathrm{AG}_{3}$ e $0,5 \mu \mathrm{M}$ de AIB.

Num segundo experimento, investigou-se a conversão dos embriões em plantas pela utilização da citocinina BAP em diferentes concentrações e os melhores resultados quanto ao comprimento das raízes e número de folhas por planta foram obtidos no tratamento de 1 $\mu \mathrm{M}$, como pode ser observado na TABELA 4 . O fenótipo das plantas em meio suplementado com BAP deu-se de forma normal, sem alterações morfológicas visualmente perceptíveis. Contudo, a conformação morfológica das plântulas mostrou-se alterada, sendo o fato representado por folhas encarquilhadas, fusionadas e coriáceas (FIGURA 4). Segundo Redenbaugh et al. (1988), para que ocorra conversão, os embriões somáticos têm de realizar uma série de eventos: germinação (emissão da radícula), crescimento e desenvolvimento do sistema radicular, produção de, no mínimo, duas folhas verdadeiras, conexão direta da raiz com a

TABELA 3 - Efeito das concentrações 5; 10 e 20ìM de 2-iP mais e 0,5 $\mu \mathrm{M}$ de AIB na maturação dos embriões somáticos (60 dias de cultivo).

\begin{tabular}{lccccc}
\hline 2-iP ( M) & $\begin{array}{c}\text { Calos com massas } \\
\text { embriogênicas (\%) }\end{array}$ & $\begin{array}{c}\text { Número de embriões } \\
\text { globulares / calo }\end{array}$ & $\begin{array}{c}\text { Número de embriões } \\
\text { cordiformes / calo }^{\mathbf{1}}\end{array}$ & $\begin{array}{c}\text { Número de embriões } \\
\text { torpedo / calo }^{\mathbf{1}}\end{array}$ & $\begin{array}{c}\text { Número de embriões } \\
\text { Cotiledonares/calo }^{\mathbf{1}}\end{array}$ \\
\hline 5 & 86,67 & 70,33 & 1,89 & 13,33 & 1,89 \\
10 & 86,67 & 46,49 & 1,44 & 5,87 & 4,55 \\
20 & 84,44 & 31,00 & 2,00 & 8,11 & 2,00 \\
\hline CV\% & 15,41 & 38,80 & 38,47 & 41,26 & 25,35 \\
\hline
\end{tabular}

As médias não diferiram significativamente pelo teste $\mathrm{F}$ da análise de variância.

${ }^{1}$ Dados transformados por arco seno da raiz de $(\mathrm{x}+0,5)$ 
TABELA 4 - Efeito das concentrações 0; 0,25; 0,5 e 1,0ìM de BAP mais e 0,5 $\mu \mathrm{M}$ de $\mathrm{AG}_{3}$ na conversão dos embriões somáticos em plantas (30 dias de cultivo).

\begin{tabular}{|c|c|c|c|c|c|}
\hline $\mathbf{B A P}(\mathbf{M})$ & $\begin{array}{c}\text { Embriões convertidos } \\
(\%)^{*}\end{array}$ & Embriões oxidad̆os (\%) & $\begin{array}{l}\text { Comprimento da parte } \\
\text { aérea }(\mathrm{cm})^{*}\end{array}$ & $\begin{array}{c}\text { Comprimento da raiz } \\
(\mathrm{cm})^{1}\end{array}$ & $\begin{array}{c}\mathbf{N}^{0} \text { folhas } \\
\text { planta }^{1}\end{array}$ \\
\hline 0,25 & 56,67 & 27,00 & 0,96 & $0,68 \mathrm{~b}$ & $0,25 \mathrm{~b}$ \\
\hline 1,0 & 56,67 & 17,00 & 0,90 & $0,92 \mathrm{a}$ & $0,66 \mathrm{a}$ \\
\hline $\mathrm{CV} \%$ & 23,18 & 18,16 & 30,52 & 23,93 & 47,30 \\
\hline
\end{tabular}

Médias seguidas por letras distintas nas colunas diferem entre si, pelo teste de Tukey, a 5\%.

* As médias não diferiram significativamente pelo teste $\mathrm{F}$ da análise de variância.

${ }^{1}$ Dados transformados para $\log (\mathrm{x}+10)$

parte aérea e produção de uma planta verde com fenótipo normal. Guerra et al. (1999) citam que o efeito das auxinas como indutoras da embriogênese somática pode também acarretar a formação de embriões anômalos quando estes passam por prolongados períodos em meios suplementados com estas substâncias. Para Raemakers et al. (1995), o desenvolvimento de embriões somáticos malformados e/ou a formação de folhas carnosas com caules fasciados é conseqüência de maturação insuficiente. Esse fenômeno tem sido observado para muitas espécies e é denominado de germinação precoce, que se refere ao embrião em desenvolvimento que tende a desviar-se dos estádios normais de embriogênese somática e adquirem características de uma plântula malformada.



FIGURA 4 - Plântulas formadas a partir de embriões somáticos cultivados durante 30 dias em meio $\mathrm{MS}^{1} / 2 \mathrm{NO}_{3}$ suplementado com 5 $\mu \mathrm{M}$ de 2 -iP, $5 \mu \mathrm{M}$ de $\mathrm{AG}_{3}$ e $0,5 \mu \mathrm{M}$ de AIB.

\section{CONCLUSÕES}

Os resultados obtidos no presente trabalho permitiram o estabelecimento do seguinte protocolo para a embriogênese somática do caquizeiro a partir de embriões zigóticos: utilizar como explantes embriões zigóticos maduros, retirados de frutos com 22 semanas de formação; cultivá-los em meio de cultura $\mathrm{MS}^{1} / 2 \mathrm{NO}_{3}$ suplementado com $10 \mu \mathrm{M}$ de $2,4-\mathrm{D}$ e $2 \mu \mathrm{M}$ de cinetina para o desenvolvimento de próembriões; transferir as culturas embriogênicas para meio basal com 5 $\mu \mathrm{M}$ de 2,4-D e $2 \mu \mathrm{M}$ de cinetina para a evolução do estádio globular; transferir as culturas embriogênicas para meio basal com 0,5 $\mu \mathrm{M}$ de AIB e 2i-P em concentrações de 5 a $20 \mu \mathrm{M}$ para a promoção dos embriões globulares a estádios mais avançados da ontogenia, como cordiforme, torpedo e cotiledonar; e transferir os embriões para meio basal com $1 \mu \mathrm{M}$ de $\mathrm{BAP}$ e $0,5 \mu \mathrm{M}$ de $\mathrm{AG}_{3}$ para a conversão em plantas.

\section{REFERÊNCIASBIBLIOGRÁFICAS}

BARROS, L.M. Embriogênese somática. Biotecnologia: Ciência e Desenvolvimento, v. 2, n.7, p.36-39, 1999.

BIASI, L.A.; CARVALHO, D.C.; WOLF, G.D.; ZANETTE, F. Potencial organogenético de tecidos caulinares e radiculares de caquizeiro. Revista Brasileira de Fruticultura, Jaboticabal, v. 24, n. 1, p. 29-34, 2002.

CHOI, J.Y; KIM, H.J.; LEE, C.H; BAE, J.M.; CHUNG, Y.S.; SHIN, J.S.; HYUNG, N.Y. Efficient and simple plant regeneration via organogenesis from leaf segment cultures of persimmon (Diospyros kaki Thunb). In Vitro Cellular \& Developmental Biology Plant, Columbia, v.37, n.2, p.274-179, 2001.

GRAY, D.J. Somatic embryogenesys and plant regeneration from immature zygotic embryos of muscadine grape (Vitis rotundifolia) cultivars. American Journal of Botany, Columbus, v.79, n.5, p.542-546, 1992.

GUERRA, M.P.; HANDRO, W. Somatic embryogenesis and plant regeneration in different organs of Euterpe edulis Mart. (Palmae): control and structural features. Journal of Plant Research, Tokyo, v.111, p.65-71, 1998.

GUERRA, M.P.; TORRES, A C.; FERREIRA, AT. Embriogênese somática e sementes sintéticas. In: TORRES, AC.; CALDAS, L. S.; BUSO, J. $\mathrm{A}$ (Ed.) Cultura de tecidos e transformação genética de plantas. Brasília: EMBRAPA-CNPH, 1999. p. 533-568.

HIROKAZU, F.; NISHIMOTO K.; MURASE, I.; NAKAMURA, M. Somatic embryogenesis from the leaf tissues of continuously subcultured shoots in Japanese Persimmon (Diospyros kaki Thunb.). Japanese Journal of Breeding, Bunkyo-Ku, n. 38, p. 465469, 1998.

MARTINS, F.P.; PEREIRA, F.M. Cultura do caquizeiro. Jaboticabal: FUNEP, 1989.71p.

RAEMAKERS, C.J.J.M.; JACOBSEN, E.; VISSER, R.G.F. Secondary somatic embryogenesis and applications in plant breeding. Euphytica, Dordrecht, v.81, p.93-107, 1995.

REDENBAUGH, K.; FUJII, J.A.; SLADE, D. Encapsulated plant embryos, In: MIZRAHI, A. (Ed.) Biotechnology in agriculture. New York: Alan R. Liss, 1988. p.225-248.

SHARP, W.P; SONDAHL, M.R.; CALDAS, L.S.; MARAFFA, S.B. The physiology of in vitro assexual embryogenesis. Horticultural Review, New York, v.2, p.268-310, 1980. 